\title{
Cyclosporin treatment does not impair the release of nitric oxide in human coronary arteries
}

Gregory S O’Neil, Adrian H Chester, Sudhir Kushwaha, Marlene Rose, Samad Tadjkarimi, Magdi H Yacoub

\begin{abstract}
Objective-It has been hypothesised that compromised endothelial function can contribute to the toxic manifestations associated with cyclosporin therapy. In vitro animal studies have implicated inhibition of release of the endothelium derived relaxing factor, nitric oxide; however, this has not been investigated in human tissue. The present study investigated the effect of cyclosporin $A$ on nitric oxide release in human coronary arteries.
\end{abstract}

Design-Study of in vitro organ bath preparations and in vivo angiographic measurements in the coronary circulation.

Patients-For the in vitro experiments coronary arteries were harvested from the excised hearts of 10 patients requiring transplantation for reasons other than ischaemic heart disease. Three of these patients were being re-transplanted for obliterative bronchiolitis and had been receiving cyclosporin for a mean of 22 months. The in vivo study was performed on a group of 12 cardiac transplant recipients who were clinically well 1-5 years postoperatively and were not undergoing allograft rejection at the time of assessment.

Results-Isolated vessel segments in vitro relaxed in a dose dependent manner in response to substance $P\left(10^{-11}-10^{-7}\right.$ mol/1). The maximum response was 76.6 $(7 \cdot 4) \%$ of the response to $1 \mu \mathrm{g} / \mathrm{ml}$ glyceryl trinitrate. Incubation with 1000 and $2000 \mathrm{ng} / \mathrm{ml}$ cyclosporin reduced the response to $63.0(11.5) \%$ and $62.2(11 \cdot 1) \%$ respectively; this was not statistically significant. In segments taken from the explanted hearts of three patients requiring re-transplantation, the mean maximum response was $78.0(11.0) \%$ and there was no correlation between maximum response in segments from each patient and the duration of cyclosporin therapy. The effect of intracoronary substance $P$ in 12 cardiac transplant recipients was also examined (mean cyclosporin blood concentration 228.9 $(42 \cdot 8) \mathrm{ng} / \mathrm{ml})$. The mean maximum dilatations measured as the percentage diameter change induced by substance $P$ and isosorbide dinitrate were $22 \cdot 1(3 \cdot 2) \%$ and $26.0(2 \cdot 5) \%$ respectively. There was no correlation between the degree of endothelium mediated vasodilatation in response to substance $P$ and cyclosporin concentration.

Conclusions-The nitric oxide response was preserved in the coronary arteries of patients exposed to cyclosporin. The mechanisms that initiate cyclosporin associated toxicity remain to be elucidated.

The outcome in patients after heart transplantation has been considerably improved by cyclosporin therapy. ${ }^{1}$ None the less, several cyclosporin associated toxic manifestations have been encountered, particularly hypertension ${ }^{2-4}$ and renal damage. ${ }^{5-9}$ The underlying mechanisms involved in the pathogenesis of these manifestations remain largely undefined. Animal studies have implicated the disruption of endothelium dependent and independent dilatation $^{10-13}$ as well as alteration in vascular response; ${ }^{1415}$ in human tissue, cyclosporin induced hypertension was associated with sympathetic neural activation. ${ }^{16}$

The effect of cyclosporin on the human coronary arterial system could have important clinical implications. Though the use of cyclosporin therapy has coincided with a decrease in accelerated atherosclerosis in grafted coronary arteries in transplant recipients, ${ }^{17}$ there is some evidence that cyclosporin can have an adverse effect on the ability of the endothelium to secrete prostacyclin ${ }^{18}$ and to enhance the production of endothelin. ${ }^{19}$ Endothelial dysfunction could have potentially harmful effects on the vessel wall and myocardium.

In a previous study we showed that acute exposure to cyclosporin at concentrations of $100-500 \mathrm{ng} / \mathrm{ml}$ did not affect the ability of the endothelium of human coronary arteries to release the endothelium derived relaxing factor, nitric oxide, in response to substance $P{ }^{20}$ After short term exposure in vitro it seems that this vasodilatory mechanism is preserved. To elucidate further the influence of cyclosporin on the endothelium we examined the effect of short term and long term exposure to therapeutic and toxic doses of cyclosporin on endothelium dependent relaxation in the human coronary circulation in vitro and in vivo. 


\section{Patients and methods}

IN VITRO STUDY

Epicardial coronary arteries were harvested from seven patients undergoing heart or heartlung transplantation for reasons other than ischaemic heart disease; they were judged to be free of atheromatous plaque both macroscopically and microscopically. After dissection, they were placed in cold, modified Tyrode's solution (composition (mmol/l): $\mathrm{NaCl} 136 \cdot 9, \mathrm{NaHCO}_{3} 11 \cdot 9, \mathrm{KCl} 2 \cdot 7, \mathrm{NaH}_{2} \mathrm{PO}_{4}$ $0 \cdot 4, \mathrm{MgCl}_{2} 2 \cdot 5, \mathrm{CaCl}_{2} 2 \cdot 5$, glucose $11 \cdot 1$, disodium EDTA 0.04 ) and gassed with $95 \%$ oxygen $/ 5 \%$ carbon dioxide for no more than eight hours.

Forty four vessel segments, 3-5 mm long; were suspended in $5 \mathrm{ml}$ organ chambers between two L-shaped metal hooks, one of which was fixed and the other attached to a Grass FTO-3C strain gauge transducer connected to a Grass 79D polygraph set up to monitor and record changes in segment tension. The temperature of the bath was maintained at $37^{\circ} \mathrm{C}$ and the Tyrode's solution was continually gassed.

A preload of $50 \mathrm{mN}$ was applied to each segment and after a stabilisation period of 40-60 minutes during which "relaxing-out" occurred and a steady baseline was reached. Potassium chloride $(90 \mathrm{mmol} / \mathrm{l})$ was applied to assess tissue viability. After washout of the potassium chloride and when a steady baseline was reached, the segments were exposed for three hours to cyclosporin (powder form donated by Sandoz). The cyclosporin was initially dissolved in methanol to give a stock solution of $0.5 \mathrm{mg} / \mathrm{ml}$ methanol; subsequent dilutions in Tyrode's solution gave final bath concentrations of 1000 and $2000 \mathrm{ng} / \mathrm{ml}$. This dilution procedure gives a uniform solution of cyclosporin in Tyrode's solution as assessed by high performance liquid chromatography (unpublished observation). During the three hour incubation period the bath solutions were renewed once. Control incubations were performed in Tyrode's solution or methanol (at a bath concentration of methanol that was identical to that used when it was used as the diluent). A level of preconstriction, optimally $60-70 \%$ of the potassium response, was then induced with cumulative doses of the thromboxane-mimetic U46619. The relaxation profiles of the preparations were examined by comparing the responses after application of substance $P\left(10^{-11}\right.$ to $\left.10^{-7} \mathrm{~mol} / \mathrm{l}\right)$ with those generated by $5.3 \times 10^{-6} \mathrm{~mol} / 1$ of glyceryl trinitrate. The ability of the vessels to respond to glyceryl trinitrate was measured against the constriction produced by U46619. In a separate study, 15 segments removed from three patients undergoing re-transplantation of the heart and lung for obliterative bronchiolitis were assessed for endothelium function as described above. These patients had been shown to have angiographically normal coronary arteries and had been treated with immunosuppressive doses of cyclosporin for a mean of 22 months; in the six week period before re-transplantation blood concentrations of the cyclosporin parent compound had ranged from 43 to $258 \mathrm{ng} / \mathrm{ml}$, and on the day before the operation concentrations were between 40 and $95 \mathrm{ng} / \mathrm{ml}$.

\section{IN VIVo STUDY}

The effect of intracoronary substance $P(1 \cdot 4$ $24 \mathrm{pmol} / \mathrm{min}$ ) and isosorbide dinitrate $(2 \mathrm{mg}$ for 2 minutes) infusion was also examined in 12 cardiac transplant recipients who were clinically well 1-5 years postoperatively. These substances possess only vasodilatory properties, and their use in this study was approved by the district ethics committee. The percentage changes in diameter were measured by a computerised analysis system (CAAS-Pie Data Medical). The blood concentrations of cyclosporin were simultaneously measured by a conventional radioimmunoassay targeted against the cyclosporin parent compound (INCSTAR Corporation). This assay measures total cyclosporin concentration in whole blood.

\section{DATA ANALYSIS}

For each patient in the in vitro studies some segments were used as controls while others were treated with only one concentration of cyclosporin. A mean value was obtained for each treatment within a patient, and these means were then averaged to give an overall mean (SEM) for each treatment for the group of patients as a whole. Treatments were compared by an unpaired $t$ test, and significance was assigned at $\mathrm{p}<0.05$.

For the in vivo study the substance $P$ and isosorbide dinitrate measurements were taken in duplicate from each patient and the means calculated. An overall mean (SEM) was then calculated for each treatment and compared by an unpaired $t$ test. Linear regression analysis was applied to examine the relation between blood concentration of cyclosporin and the response to substance $P$ and isosorbide dinitrate.

\section{Results}

In vitro study-We studied vessels removed from hearts at time of transplantation ( 3 hour cyclosporin incubation-acute effect) or retransplantation (chronic effect). Substance $P$

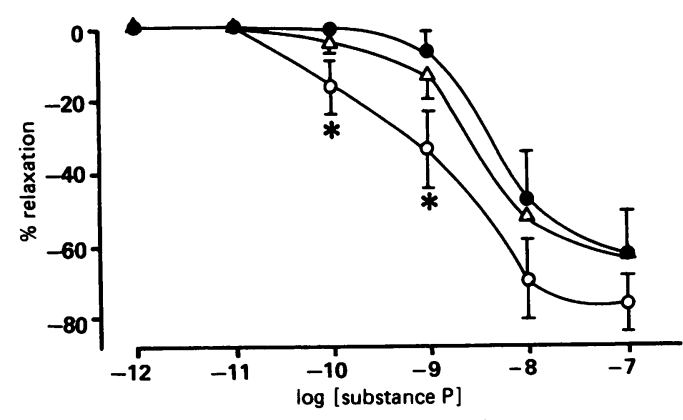

Figure 1 Effect of cyclosporin on the relaxation induced by substance $P\left(10^{-11}-10^{-7}\right.$ moll l) in human epicardial coronary arteries $(O=$ control, 16 segments from 7 coronary arteries $\Delta=1000 \mathrm{ng} / \mathrm{ml}$ cyclosporin, 14 segments from 7 patients; $=2000 \mathrm{ng} / \mathrm{ml}$ cyclosporin, 14 segments from 7 patients). Responses are mean (SEM) of from 7 patients). Responses are mean (SEMts from seven patients, measured as percentage of relaxation in response to $5 \cdot 3 \times 10^{-6} \mathrm{~mol} / \mathrm{l}$ glyceryl trinitrate. ${ }^{\star} p<0.05$. 


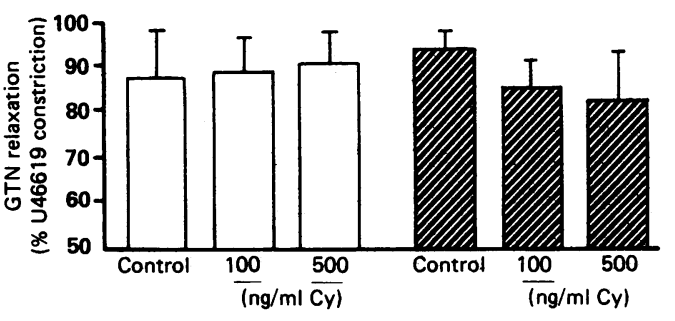

Figure 2 Effect of cyclosporin (Cy) (100-2000 $\mathrm{ng} / \mathrm{ml})$ on the relaxation induced by $5 \cdot 3 \times 10^{-6}$ moll l glyceryl. trinitrate (GTN) in human epicardial coronary arteries. Open columns: control $=12$ segments from four patients; $100 \mathrm{ng} / \mathrm{ml}$ cyclosporin $=12$ segments from four patients; and $500 \mathrm{ng} / \mathrm{ml}$ cyclosporin $=12$ segments from four patients. Responses are means (SEM) of segments from four patients. Hatched columns: control $=16$ segments from seven patients; $1000 \mathrm{ng} / \mathrm{ml}$ cyclosporin $=14$ segments from seven patients; and $2000 \mathrm{ng} / \mathrm{ml}$ cyclosporin $=14$ segments from seven patients. Responses are means (SEM) of segments from seven patients measured as percentage of constriction in response to U46619.

caused dose dependent relaxation in all vessel segments. In the control tissue maximum relaxation was $76.6(7 \cdot 4) \%$ in response to $10^{-7} \mathrm{~mol} / 1$ substance $P$. This was unaffected by incubation with the methanol vehicle. After incubation with $1000 \mathrm{ng} / \mathrm{ml}$ and $2000 \mathrm{ng} / \mathrm{ml}$ cyclosporin the maximum relaxations were $63.0(11.5) \%$ and $62.2(11.1) \%$ respectively. This reduction in the vasodilatory response was not statistically significant. However, at low concentrations of substance $P\left(10^{-10}\right.$ and $10^{-7} \mathrm{~mol} / \mathrm{l}$ ) the dilatatory response was significantly reduced $(p<0.05)$ (fig 1$)$. Cyclosporin caused a mild but non-significant reduction $(p>0.05)$ of the relaxations produced by $5.3 \times 10^{-6} \mathrm{~mol} / 1$ glyceryl trinitrate: $1000 \mathrm{ng} / \mathrm{ml}, 82 \cdot 3(4 \cdot 3) \%, 2000 \mathrm{ng} / \mathrm{ml}$, $82.0(6.4) \%$, control, $92.8(2.4) \%$ (fig 2 ). This trend was not seen when lower concentrations of cyclosporin were used. ${ }^{20}$

Segments of coronary artery from the retransplanted patients had a mean maximum response to $10^{-7} \mathrm{~mol} / 1$ substance $P$ of 78.0 $(11.0) \%$, which was similar to that of the control tissue. The dose response curves were parallel for each patient although the maximum response varied (fig 3 ). There was no correlation

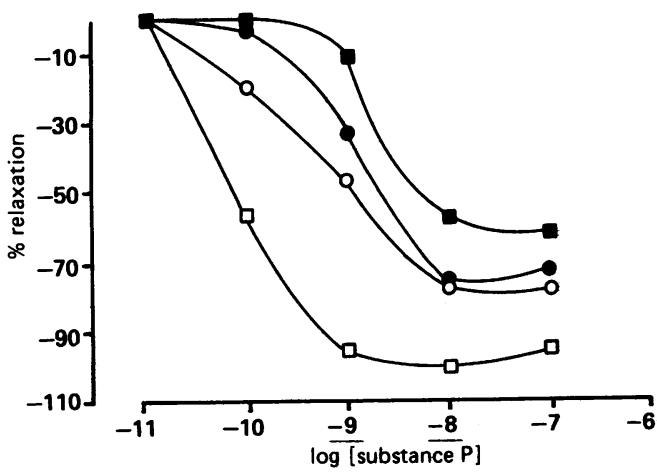

Figure 3 Relaxations to substance $P\left(10^{-11}-10^{-7} \mathrm{~mol} / \mathrm{l}\right)$ in 15 segments of epicardial coronary artery from three patients undergoing re-transplantation for obliterative bronchiolitis (O, mean of three patients). Patient 1 ( 2 days cyclosporin therapy; patient 2 (O) 30 months cyclosporin therapy; patient 3 ( $\square$ ) 37 months cyclosporin therapy.
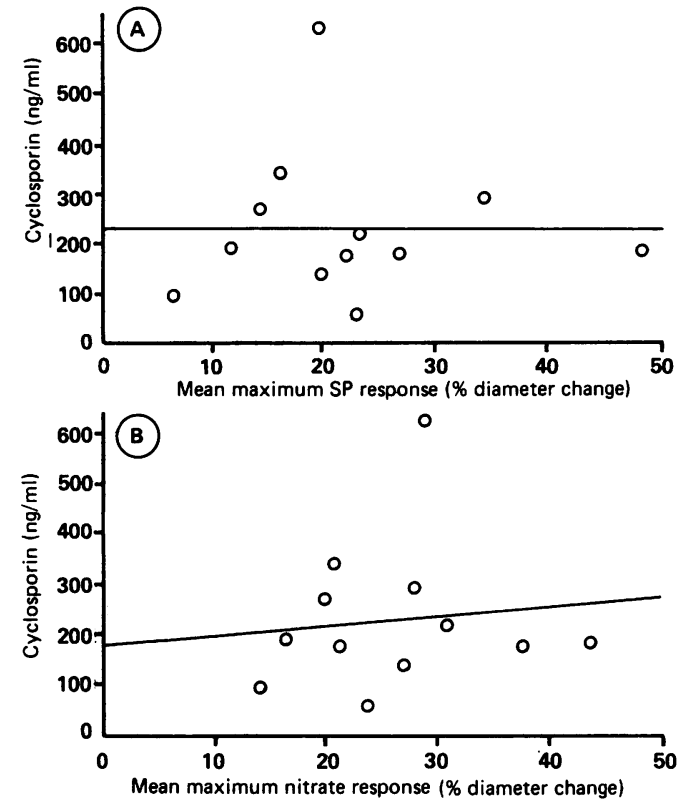

Figure 4 Correlation curves for blood cyclosporin concentrations and the in vivo responses to $(A)$ substance $P(S P)$ and $(B)$ isosorbide dinitrate (ISDN) measured as percentage vessel diameter change after intracoronary $S P$ (1.4-24 pmol/min) and ISDN (2 $\mathrm{mg}$ for $2 \mathrm{~min}$ ) infusion in 12 cardiac transplant recipients assessed 1-5 years postoperatively.

between maximum response and duration of cyclosporin treatment.

In vivo study-We examined angiograms of the coronary arteries of 12 transplant recipients 1-5 years postoperatively. The mean maximum dilatations in response to substance $P$ and isosorbide dinitrate were $22 \cdot 1(3 \cdot 2) \%$ and $26 \cdot 0$ $(2.5) \%$ respectively. These were significantly different from the control value $(p<0.05)$ but not significantly different from each other. There was no correlation between the blood concentration of cyclosporin and the response to either substance $\mathrm{P}$ or isosorbide dinitrate (fig $4 A$ and $B$ ).

\section{Discussion}

We examined the short and long term consequences of therapeutic and toxic exposure to cyclosporin in vitro and in vivo. We showed that cyclosporin does not affect the ability of human coronary arteries to release nitric oxide in response to substance $P$.

Nitric oxide, released from vascular endothelium, is thought to be important in guarding against vasospasm and platelet aggregation. ${ }^{21-23}$ The consequences of compromised nitric oxide release are now considered to be far-reaching in the human vascular system. ${ }^{24-26}$ Loss of the protective anti-spastic and anti-aggregatory properties of nitric oxide seems to predispose toward constrictor and thrombotic events. Hypertension, renal damage, and atherosclerosis could be caused or aggravated by malfunction of the endothelium.

Nitric oxide release was reduced in animal preparations treated with cyclosporin. Specific endothelial damage was shown to be associated with the duration of cyclosporin administra- 
tion. Thus after three hours ${ }^{10}$ and five days ${ }^{11}$ the ability of the endothelium of rat aortic rings to produce nitric oxide was affected but the complete response to endothelium independent vasodilatation with nitrates was retained. However after three weeks ${ }^{13}$ and eight weeks ${ }^{11}$ the smooth muscle response was reduced; so the assessment of a specific effect on the release of endothelium derived nitric oxide is difficult. We also found that in the isolated rat heart the endothelium dependent and independent responses were reduced by cyclosporin. In human tissues there seems to be a loss in the sensitivity of the relaxatory response at low concentrations of substance P; however, the nitric oxide and nitrate maximum responses are not significantly compromised. This holds true for a range of cyclosporin concentrations in both acute and chronic experiments. At high doses in vitro there was a blunting of the nitrate response which did not reach statistical significance. It is therefore possible that prolonged exposure to toxic concentrations of cyclosporin may produce smooth muscle damage.

The results obtained in coronary arteries from re-transplantation can be regarded as preliminary data from a small group of patients. They serve to confirm that the preservation of the response as measured in the in vivo study is reproducible in the isolated organ bath and that the duration of cyclosporin treatment does not correlate with inhibition of nitric oxide release.

Despite the results from the in vitro experiments, it is still possible that patients who were treated with cyclosporin for months and years have altered endothelial function. This question cannot be adequately addressed by in vitro techniques because we could only obtain a small number of arteries from patients who had been receiving cyclosporin. Therefore, the in vivo study was designed to examine the consequences of chronic exposure of the endothelium to therapeutic concentrations of cyclosporin. The mean vasodilatatory response to substance $P$ was not significantly different from the responses obtained in normal nontransplanted patients with no coronary artery disease ${ }^{27}$ Chronic exposure to cyclosporin did not seem to alter endothelial function as assessed by the ability of substance $P$ to release nitric oxide in the coronary arteries of cardiac transplant patients. We used substance $P$ to assess endothelial function because it has a vasodilatatory action only. Previous studies of acetylcholine infusion in transplant recipients suggested endothelial dysfunction because it caused vasoconstriction. ${ }^{28}$ However, acetylcholine produced vasoconstriction in any vessel when a high enough dose was used, ${ }^{29}$ which makes it an unreliable agent for the examination of endothelium mediated dilatation.

Cyclosporin affected some endothelial functions; factor VIII concentration increased ${ }^{30}$ while prostacyclin production was impaired ${ }^{18}$; concentrations of endothelin, the potent endothelium derived constrictor, were raised. ${ }^{19}$ However, our study has shown that the capacity to release nitric oxide is preserved in human coronary endothelium. Cyclosporin does inhibit endothelial prostacyclin production, ${ }^{18}$ although there has been conflicting experimental evidence on prostaglandin excretion in cyclosporin nephrotoxicity. ${ }^{31}$ It seems that interaction of cyclosporin with endothelium derived vasodilatators has no direct role in the genesis of hypertension, renal damage, and accelerated graft atherosclerosis in the transplant recipient. It is more likely that the vasospasm and vascular damage associated with cyclosporin toxicity is caused by a combination of effects on constrictor influences (such as endothelin ${ }^{19}$ and thromboxan $e^{32-34}$ ) as well as a possible direct effect of cyclosporin on smooth muscle. ${ }^{145-37}$ These may be superimposed on the observed increase in sympathetic nerve activity. ${ }^{16}$

We conclude that the nitric oxide response remains unaffected in coronary arteries of patients exposed to cyclosporin. The mechanisms of vascular damage in patients receiving cyclosporin need further elucidation if we are to evolve rational methods of preventing this important complication.

1 Cohen DJ, Loertscher R, Rubin MF, Tilney NL, Carpenter CB, Strom TB. Cyclosporine: a new immunosuppressive agent for organ transplantation. Ann Intern Med 1984 101:667-82.

2 Thompson ME, Shapro AP, Johnson AM, et al. New onset of hypertension following cardiac transplantation: preliminary report and analysis. Transplant Proc 1983 15(suppl 1):2573-7.

3 Olivari M-T, Antolick A, Ring WS. Arterial hypertension in heart transplant recipients treated with triple-drug immunosuppressive therapy. J Heart Transplant 1989; 8:34-9.

4 Bennett WM, Porter GA. Cyclosporin-associated hypertension. Am J Med 1988;85:131-3.

5 Myers BD, Sibley R, Newton L, et al. The long-term course of cyclosporine-associated chronic nephropathy. Kidney of cyclosporine-associtt
Int $1988 ; 33: 590-600$.

6 Sweny P, Hopper J, Gross M, Varghese Z. Nephrotoxicity of cyclosporin A. Lancet 1981;i:663-4.

7 Bennett WM, Pulliam JP. Cyclosporin nephrotoxicity. Ann Intern Med 1983;99:851-5.

8 Neild GH, Reuben R, Hartley RB, Cameron JS. Glomerula thrombi in renal allografts associated with cyclosporin treatment. J Clin Pathol 1985;38:253-8.

9 Sommer BG, Innes JT, Whitehurst RM, Sharma HM, Ferguson RM. Cyclosporin-associated renal arteriopathy resulting in loss of allograft function. Am J Surg 1985; 149:156-64.

10 Dinh Xuan AT, Fan TPD, Higenbottam TW, Clelland C, Wallwork J. Cyclosporin in vitro reduces endotheliumdependent relaxation to acetylcholine but does not affect relaxation to nitrovasodilators. Transplant Proc 1990; 22:1723-5.

11 Bossaller C, Förstermann U, Hertel R, Olbricht C, Reschke V, Fleck E. Ciclosporin A inhibits endothelium-depen$\mathrm{V}$, Fleck $\mathrm{E}$. Ciclosporin $\mathrm{A}$ inhibits endothelium-dependent vasodilation and vascular p
Eur J Pharmacol 1989;165:165-9.

12 Rego A, Vargas R, Wroblewska B, Foegh ML, Ramwell PW. Attenuation of vascular relaxation and cyclic GMP responses by cyclosporin A. J Pharmacol Exp The 1990;252:165-70.

13 Rego A, Vargas R, Foegh ML, Ramwell PW. Effect of ciclosporin A treatment on vascular reactivity of the rat thoracic aorta. Transplant Proc 1988;20(suppl 3):572-7.

14 Golub MS, Lustig S, Berger ME, Lee DBN. Altered vascular responses in cyclosporin-treated rats. Transplantation $1989 ; 48: 116-8$.

15 Rego A, Vargas R, Suarez KR, Foegh ML, Ramwell PW Mechanism of cyclosporin potentiation of vasoconstriction of the isolated rat mesenteric arterial bed: role of extracellular calcium. J Pharmacol Exp Ther 1990 254:799-808

16 Scherrer U, Vissing SF, Morgan BJ, et al. Cyclosporininduced sympathetic activation and hypertension after induced sympathetic activation and hypertension a

17 Barbir M, Banner NR, Reid CJ, Thompson GR, Mitchell arbir M, Banner NR, Reid CJ, Thompson GR, Mitchell AG, Yacoub MH. Influence of lipid abnormalities on the development of coronary arterial disease after card
transplantation [abstract]. Br Heart J 1989;61:462.

18 Brown Z, Neild GH. Cyclosporin inhibits prostacyclin rown Z, Neild GH. Cyclosporin inhibits prostacyclin production by cultured hum

19 Cairns HS, Rogerson M, Fairbanks LD, Westwick J, Neild GH. Endothelin and cyclosporin nephrotoxicity. Lancet 1988;ii:1496-7. 
20 O'Neil GS, Chester AH, Rose M, Tadjkarimi S, Yacoub $\mathrm{MH}$. The effect of cyclosporin $\mathrm{A}$ on the release of endothelium-derived relaxing factor from isolated human epicardial coronary arteries. Transplantation 1991; 51:735-8.

21 Lüscher TF. Endothelial vasoactive substances and cardiovascular disease. Basel: S Karger, 1988:1-130.

22 Radomski MW, Palmer RMJ, Moncada S. The antiaggregatory properties of vascular endothelium: interaggregatory properties of vascular endothelium: intermacol 1987;92:639-46.

23 Bassenge E, Busse R. Endothelial modulation of coronary tone. Prog Cardiovasc Dis 1988;30:349-80.

24 Chester AH, O'Neil GS, Moncada S, Tadikarimi S, Yacoub MH. Low basal and stimulated release of nitric oxide in MH. Low basal and stimulated release of nitric oxide in
atherosclerotic epicardial coronary arteries. Lancet 1990; atherosclero

25 Bossaller C, Habib GB, Yamamoto H, Williams C, Wells S, Henry PD. Impaired muscarinic endothelium-dependent relaxation and cyclic guanosine 5'-monophosphate formation in atherosclerotic human coronary artery and rabbit aorta. J Clin Invest 1987;79:170-74.

26 Lüscher TF, Diedrich D, Siebenmann R, et al. Difference between endothelium-dependent relaxation in arterial and in venous coronary bypass grafts. $N$ Engl J Med 1988; 319:462-7.

27 Crossman DC, Larkin SW, Fuller RW, Davies GJ, Maseri A. Substance $\mathbf{P}$ dilates epicardial coronary arteries and increases blood flow in humans. Circulation 1989;80: incre-84.

28 Nellessen U, Lee TC, Fischell TA, et al. Effects of acetyl- choline on epicardial coronary arteries after cardiac transplantation without evidence of fixed graft recording. $\mathrm{Am}$ Cardiol 1988;62:1093-7.

29 Newman CM, Hackett DR, Fryer M, El-Tamimi HM Davies GJ, Maseri A. Dual effects of acetylcholine on angiographically normal human coronary arteries in vivo. Circulation 1987;76(suppl IV):238-45.

30 Brown Z, Neild GH, Willoughby JJ, et al. Increased factor VIII as an index of vascular injury in cyclosporin nephrotoxicity. Transplantation 1986;42:150-3.

31 Neild GH. Cyclosporin nephrotoxicity. Seminars in Thoracic and Cardiovascular Surgery 1990;2:198-203.

32 Kawaguchi A, Goldman MH, Shapiro $\mathrm{R}$, et al. Increase in urinary thromboxane B2 in rats caused by cyclosporin. urinary thromboxane $B 2$ in rats

33 Petric R, Freeman D, Wallace C, McDonald J, Stiller C Keown P. Modulation of experimental cyclosporin nephrotoxicity by inhibition of thromboxane synthesis Transplantation 1990;50:558-63.

34 Perico N, Benigni A, Zoja C, et al. Functional significance of exaggerated renal thromboxane A2 synthesis induced by cyclosporin A. Am J Physiol 1986;251:F581-7.

35 Xue H, Bukoski RD, McCarron DA, Bennett WH. Induction of contraction in isolated rat aorta by cyclosporine Transplantation 1987;43:715-8.

36 Pfeilschifter J, Ruegg UT. Cyclosporin A augments angiotensin II-stimulated rise in intracellular free calcium in vascular smooth muscle cells. Biochem J 1987;248:883-7.

37 Meyer-Lehnert H, Schrier RW. Cyclosporin A enhances vasopressin-induced $\mathrm{Ca}^{2+}$ mobilization and contraction in mesangial cells. Kidney Int 1988;34:89-97. 